\title{
Stem cell therapies for acute spinal cord injury in humans: a review
}

\author{
*Michael C. Jin, BS, Zachary A. Medress, MD, Tej D. Azad, MS, Vanessa M. Doulames, PhD, and \\ Anand Veeravagu, MD
}

Department of Neurosurgery, Stanford University School of Medicine, Stanford, California

\begin{abstract}
Recent advances in stem cell biology present significant opportunities to advance clinical applications of stem cellbased therapies for spinal cord injury (SCI). In this review, the authors critically analyze the basic science and translational evidence that supports the use of various stem cell sources, including induced pluripotent stem cells, oligodendrocyte precursor cells, and mesenchymal stem cells. They subsequently explore recent advances in stem cell biology and discuss ongoing clinical translation efforts, including combinatorial strategies utilizing scaffolds, biogels, and growth factors to augment stem cell survival, function, and engraftment. Finally, the authors discuss the evolution of stem cell therapies for SCl by providing an overview of completed $(n=18)$ and ongoing $(n=9)$ clinical trials.
\end{abstract}

https://thejns.org/doi/abs/10.3171/2018.12.FOCUS18602

KEYWORDS stem cell; spinal cord injury; transplant; trauma; clinical trials

$\mathrm{S}$ PINAL cord injury (SCI) is defined by a complex pathophysiological cascade provoked by mechanical injury to the spinal column. The global incidence of acute SCI is approximately 10 cases per 100,000 persons, resulting in over 700,000 new cases diagnosed per year worldwide. ${ }^{28}$ The economic impact attributed to the care of SCI patients is substantial, with estimated first-year costs at over $\$ 500,000$ per individual with additional annual charges of nearly $\$ 100,000$ for the remainder of the patient's life. ${ }^{10,36}$

SCI pathophysiology consists of two distinct phases. Primary injury refers to the initial shearing or compression of the spinal cord tissue. The mechanical force of the primary injury causes hemorrhage, disruption of cell membrane integrity, and ion and neurotransmitter imbalance that immediately compromises neural function. Secondary injury pertains to the progressive inflammatory, ischemic, and apoptotic cascade that follows the initial mechanical assault. ${ }^{52}$ Stem cell therapies for SCI seek to minimize the spread of secondary injury, augment the function of remaining cell populations, and facilitate regeneration of neuronal and glial populations. In this review article, we explore cell-based therapies targeting acute SCI, with a focus on completed and ongoing clinical trials.

\section{History of Cell-Based Therapies}

Stem cells have the unique ability to undergo asymmetrical division, generating a daughter stem cell and an additional progenitor cell. The repertoire of phenotypes that a stem cell is capable of maturing into defines its potency, with totipotency referring to the ability to differentiate into all terminal cell populations and multipotency defining stem cells only able to pursue a subset of lineages. Advances in stem cell biology have allowed for direct modulation of differentiation pathways and the ability to generate relatively homogeneous terminally differentiated cell populations from totipotent and multipotent cells. Transplanta-

\footnotetext{
ABBREVIATIONS AD-MSC = adipose-derived MSC; ASIA = American Spinal Injury Association; BDNF = brain-derived neurotrophic factor; BMP = bone morphogenetic protein; $\mathrm{BM}-\mathrm{MSC}=$ bone marrow-derived MSC; $\mathrm{ESC}=$ embryonic stem cell; $\mathrm{PSC}=$ induced pluripotent stem cell; $\mathrm{MEP}=$ motor evoked potential; $\mathrm{MSC}=$ mesenchymal stem cell; NPC = neural progenitor cell; OPC = oligodendrocyte progenitor cell; $\mathrm{SCl}=$ spinal cord injury; TGF $\beta=$ transforming growth factor- $\beta$; U-MSC = umbilical cord MSC. SUBMITTED November 1, 2018. ACCEPTED December 11, 2018.
}

INCLUDE WHEN CITING DOI: 10.3171/2018.12.FOCUS18602.

${ }^{*}$ M.C.J. and Z.A.M. contributed equally to this work. 
tion of multipotent neural progenitors has been shown in rodent models to be sufficient for promoting axon elongation and synapse formation in spite of the postinjury inhibitory milieu. ${ }^{33}$ Early investigations into the potential of directed differentiation centered around deriving neural lineage cell populations from human embryonic stem cells (ESCs), with functional studies demonstrating transplantation of these derived populations encouraged behavioral and sensorimotor recovery in small rodent models of acute SCI. ${ }^{15,25,35,47,59}$ Clinical exploration of cell transplant therapy in acute SCI patients led to the initiation of a 2010 Geron Corporation trial exploring introduction of human ESC-derived oligodendrocyte progenitor cells (OPCs) into the lesion site. ${ }^{16}$ Since then, investigations into cellbased therapies have expanded on multiple frontiers, from the derivation of transplantable cells from neural progenitors to the establishment of a multitude of methods for optimizing transplant delivery (Table 1).

\section{ESC-Derived Therapies}

ESCs are regarded as the archetypal stem cell, with the capacity to endlessly self-renew and the ability to differentiate into any cell lineage. ${ }^{26}$ Maintenance of this state is nontrivial, requiring stringent regulation of cell-cycle progression and conservation of genomic stability. Human ESCs specifically require the modulation of an intricate series of activating and inhibitory pathways, including but not limited to the inhibition of bone morphogenetic proteins (BMP2 and BMP4), activation of transforming growth factor $-\beta$ (TGF $\beta$ ) and involvement of Wnt pathway proteins. ${ }^{13,47}$ Retention of genomic stability is largely associated with maintenance of telomere integrity by upregulation of telomerase activity and promotion of DNA repair pathways involved in replication error repair and oxidative stress. ${ }^{2,13}$ Satisfaction of these two prerequisites, along with upregulation of the critical transcription factors Oct 3 / Oct4, Sox2, Klf4, and c-Myc, is sufficient for indefinite maintenance of a pluripotent state. ${ }^{57}$

The ability to direct differentiation along neural fates offers intriguing glimpses into the potential of stem cell therapy in acute SCI. The induced differentiation of ESCs into neural progenitors, cells restricted to neuronal and glial lineages, has been explored using various protocols to manipulate in vitro conditions to direct cell maturation. ${ }^{18,60,68,70}$ Transplantation of these neural progenitors into animal models of acute SCI has yielded promising results, including transplant integration, axonal elongation, tract regeneration, oligodendrocyte-induced remyelination, and restoration of neuromuscular junctions. . $^{15,18,35}$ Assessment of hindlimb functionality and gait suggests that the transplantation of ESC-derived neural progenitors encourages modest recovery of motor function..$^{15,25,35}$

Significant functional, legal, and ethical shortcomings, however, have limited the application of ESCs in human SCI. ${ }^{41}$ Acquisition of ESCs involves the isolation of embryonic cells from the inner cell mass of the developing blastocyst, one of the final phases in which germ cells retain pluripotency and self-renewing capabilities; this, however, results in the destruction of the blastocyst, raising significant ethical concerns. ${ }^{62}$ Additionally, the formation of teratomas, tumors masses composed of structurally and compositionally heterogeneous aggregates of differentiated somatic tissue, has been observed in numerous animal models of ESC-derived cell therapy. ${ }^{40,58}$ Molecular characterization of human ESC teratomas has provided insight into potentially targetable oncogenic pathways, allowing for future investigations into methods for ablation of tumorigenic potential. ${ }^{4}$

\section{Transition to Alternative Stem Cell Types}

Given the controversies surrounding ESCs, focus has transitioned to mesenchymal stem cells (MSCs) and induced pluripotent stem cells (iPSCs) as multipotent alternatives to human ESCs. Unlike human ESCs, MSCs can be readily harvested from adults and are obtained from a number of organs and tissues, including bone marrow and adipose tissue. ${ }^{64}$ In addition, the opportunity to harvest and transplant cells autologously greatly reduces concerns regarding immunogenicity and graft rejection. MSC-derived cell transplant therapies also have been shown in animal models to reduce spinal cord damage associated with immune activation by secondary injury. ${ }^{1}$ Finally, the ability of MSCs to "home" to the injury site allows for noninvasive methods of cell transplantation, including peripheral injection. ${ }^{44,65}$ Despite these advantages, MSCs also bring distinct limitations, including their inherent multipotency that restricts the repertoire of available cell fates.

In particular, studies have explored the therapeutic potential of OPCs, bone marrow-derived (BM-MSCs), adipose-derived (AD-MSCs), and umbilical cord (U-MSCs) MSCs in the context of SCI.

\section{OPCs}

Demyelination of axonal projections resulting from the destruction of local oligodendrocyte populations is a hallmark of secondary SCI. Transplantation of OPCs (also referred to as oligodendrocyte precursor cells) may mediate loss of myelination and attenuate further injury. In vivo studies have demonstrated significant therapeutic potential in the transplantation of OPCs in contusive SCI models. Implanted OPCs are capable of full differentiation into mature oligodendrocytes and promote remyelination of damaged axons near the injury site. ${ }^{6}$ Phenotypic recovery of motor function has additionally suggested a restorative benefit associated with OPC transplantation. Histological findings correlate with this observed improvement, demonstrating preservation of white matter in experimental groups exhibiting the greatest functional improvement. ${ }^{30}$ Evaluation of motor evoked potentials (MEPs) revealed reduced latency periods in animals receiving OPC transplants and confirmed recovery of motor system conduction.

Despite substantial research exploring OPC transplantation as a potential therapeutic avenue in SCI management, there remains a shortage of longitudinal clinical trials demonstrating efficacy in humans. An ongoing phase I/II dose-escalation trial by Asterias Biotherapeutics aims to evaluate human ESC-derived OPC transplants in cervical SCI and was expected to reach completion by December 2018 (Table 2; NCT02302157). Interim results from 


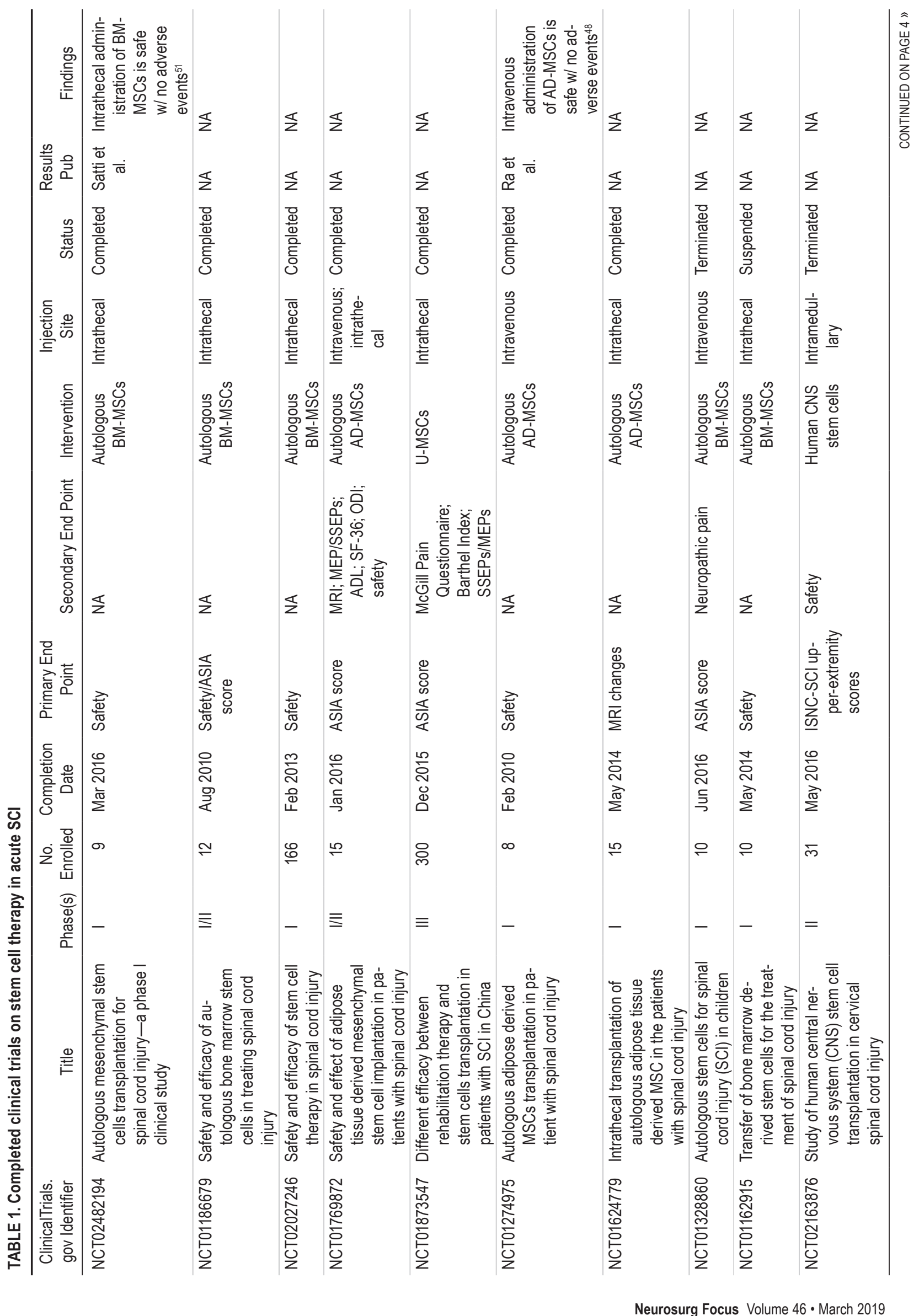




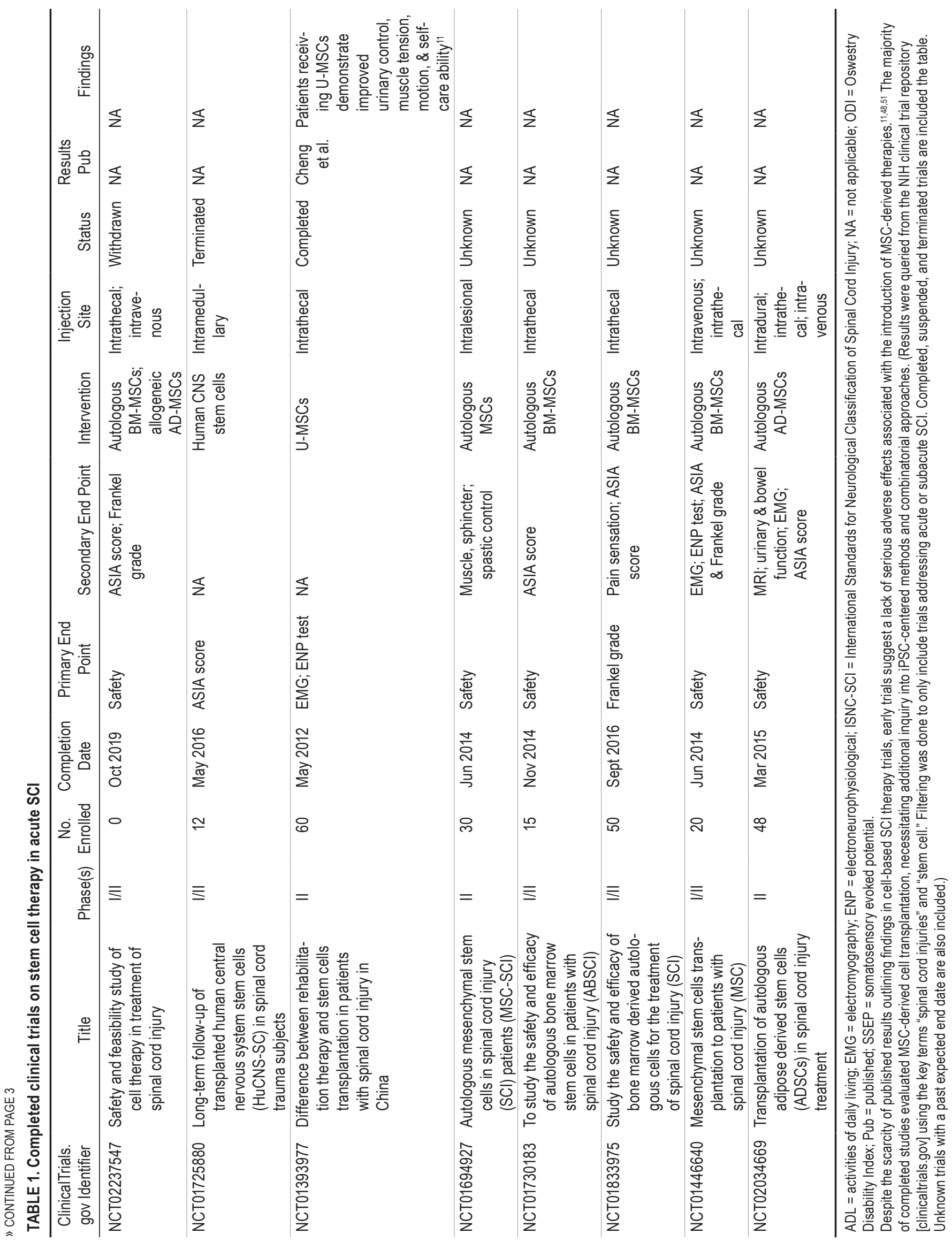




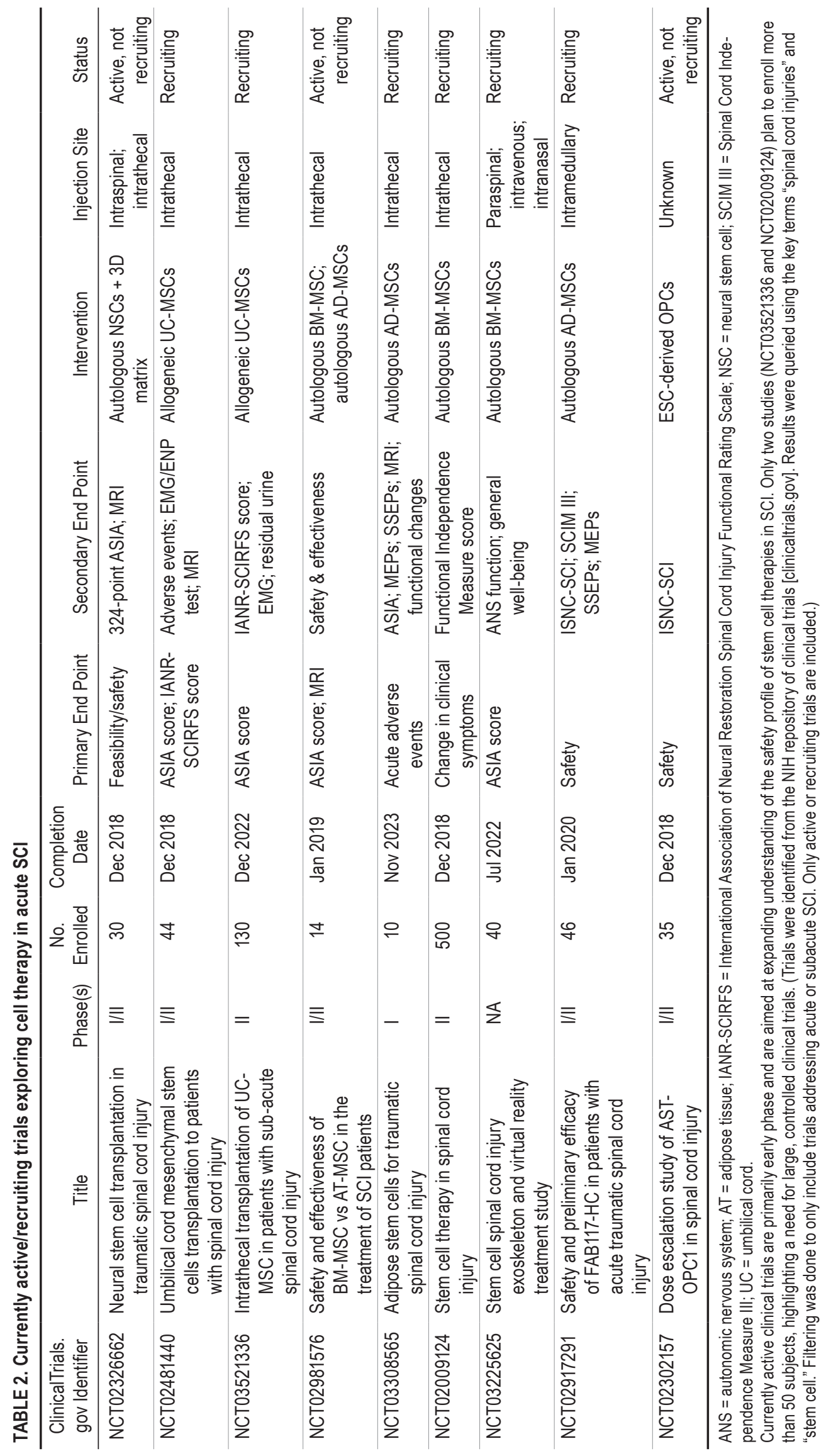


the first cohort of patients evaluated suggest a promising safety profile, with no reported severe adverse side effects 24 months following treatment. ${ }^{3}$ Continued evaluation is ongoing, but preliminary reports include MRI evidence of cell attachment and tissue formation. Longitudinal evaluation of changes in American Spinal Injury Association (ASIA) motor score indicates upper-extremity motor improvements in 5 of 6 patients. Despite promising initial results, additional validation is needed in the form of larger transplant cohorts and additional phase II and III trials.

\section{BM-MSCs}

BM-MSCs are partially differentiated progenitor cells that reside within adult bone marrow and support continual hematopoiesis and bone regeneration. ${ }^{9}$ Originally believed to be tripotent, additional studies have shown that BM-MSCs are capable of pursing a broad range of lineages and can propagate populations expressing a variety of neural markers. ${ }^{66}$ Early in vivo research established that the introduction of BM-MSCs into the injury site of rats suffering from spinal cord contusion resulted in the robust formation of tissue bundles hosting populations of astrocyte and neuronal predecessors. ${ }^{21}$ Delayed introduction of BM-MSCs into the injury site was found to improve functional recovery of hindlimb motility and strength. Further molecular characterization of BM-MSC intravenous transplantation models suggested that functional recovery was preceded by expanded production of neurotropic factors (brain-derived neurotrophic factor [BDNF] and nerve growth factor) and vascular endothelial growth factor. ${ }^{12}$ BDNF and nerve growth factor have previously been demonstrated to be critical regulators in neuronal differentiation, while vascular endothelial growth factor is known to be a key contributor to the initiation and continued induction of angiogenesis and vasculogenesis. ${ }^{20,31}$

In one of the first longitudinal studies examining BMMSC-based therapy in patients with cervical SCI, autologous BM-MSCs isolated from the iliac bone of each patient were expanded and introduced via injection (both intramedullary and intradural). Within 6 months of transplantation, improved upper-extremity motor function and MRI changes were observed in 6 and 7 of the 10 candidate patients, respectively. ${ }^{23}$ These patients were tracked for over 3 years posttransplantation, and continued observation of recovery progress demonstrated continuous improvement in upper-extremity functionality with no evidence of complications or tumor formation. ${ }^{46}$ Additional trials would help confirm the clinical efficacy of BM-MSCs, especially in light of conflicting reports disputing the extent to which patients respond to BM-MSC treatment. ${ }^{45,55}$ In addition to completed studies, we identified 3 ongoing phase I and II trials exploring BM-MSC-based therapies in acute SCI patients (Table 2). For each of these studies, functional improvements were measured according to a graded scale (e.g., ASIA) and, combined, they seek to enroll 554 total patients. One study in particular, named SciExVR, aims to integrate other therapeutic modalities, namely exoskeletal stimulation and virtual reality visualization, following paraspinal, intravenous, and intranasal application of BMMSCs to explore the potential benefit of combinatorial therapies centered around BM-MSCs (NCT03225625).
The completion of these studies will provide much-needed information to initiate larger-scale efforts scrutinizing the functional efficacy of BM-MSC-derived therapies.

\section{U-MSCs}

Recent investigations have also examined the utility of MSCs recovered from tissue sources outside of bone marrow, including umbilical cord and adipose tissue.,32 U-MSCs specifically demonstrate the potential to mature into relatively homogeneous populations expressing neural markers, acquiring phenotypic traits, such as end branching and bipolar extensions, that are characteristic of terminally differentiated neurons and their predecessors. Furthermore, immunostaining for neural biomarkers demonstrates extensive expression of cytoskeletal proteins specific to neurons and astrocytes. ${ }^{19}$ In an early study of intravenous transplantation of human U-MSCs, rats suffering from compressive SCI demonstrated significant functional recovery. ${ }^{50}$ Additionally, U-MSCs were found to migrate to the injury site within 4 weeks of transplantation. Later studies demonstrated additional benefit associated with coinjection of BDNF with U-MSCs compared to injection of only U-MSCs. Immunohistochemistry for GFAP/MAP2 confirmed differentiation into the astrocytic and neural lineages, respectively. ${ }^{27}$ Anatomical improvements at the injury site were also observed after transplantation of U-MSCs, noting increased angiogenesis and reduced glial scar formation due to upregulation of matrix metalloproteinases. ${ }^{37,63}$

Clinically, injection of U-MSCs into the subarachnoid, intradural, and extradural spaces of the spinal cord in a patient suffering from a compressive fracture has demonstrated improved motor function in the lower extremities, and CT and MRI demonstrated expansion of the atrophied spinal cord, particularly at the injured level. ${ }^{24}$ However, additional efforts are needed to more comprehensively evaluate the effectiveness of U-MSC transplantation in acute SCI. A recently initiated phase II trial has started enrollment of patients into a multicenter, randomized, shamcontrolled study evaluating the safety and efficacy of intrathecal transplantation of U-MSCs into patients with acute, subacute, and chronic SCI (Table 2; NCT03521336). Functional progress scores based on the ASIA Scale, the International Association of Neural Restoration of Spinal Cord Injury Rating Scale, and electromyogram testing serve as clinical end points and completion of the study is expected by late 2022 .

\section{AD-MSCs}

AD-MSC transplants have also been explored as an alternative to ESC-based therapy. Compared to bone marrow, adipose tissue contains a greater population of somatic stem cells, which, combined with the ubiquitous availability of adipose tissue, has made AD-MSCs an attractive source of transplantable MSCs..$^{14,71}$ Functional experiments indicate that intravenous application of AD-MSCs improve hindlimb motor function through activation of angiogenesis along with upregulation of upstream kinase protein activity, such as ERK1/2 and Akt, in turn promoting cellular survival pathways and tissue-repair mechanisms. ${ }^{42}$ However, while AD-MSC transplantation has been evaluated 
in animal SCI models, there remains a paucity of large, longitudinal clinical trials utilizing stem cells derived from adipose tissue. Early studies examining the safety of intravenous injection of AD-MSCs reported no adverse side effects, including no observed tumorigenicity ${ }^{48}$ One recent study investigated the effect of intrathecal transplantation of autologously collected AD-MSCs in 14 patients with SCI. ${ }^{22}$ Functionality was measured using the ASIA motor and sensory scores, while corresponding electrophysiological studies included electromyography and MRI examinations. Following treatment, 10 of the 14 patients exhibited sensory improvement; however, lesion size, as visualized by MRI, remained stable. Severe adverse events were also absent from all of the patients treated with AD-MSCs. While 3 patients developed minor side effects following therapy, these events were thought to be unrelated to the treatment itself.

We identified 3 ongoing clinical trials exploring the safety and efficacy of AD-MSCs and AD-MSC-derived therapies (Table 2; NCT02917291). The most comprehensive of these is a phase I/II trial investigating FAB117$\mathrm{HC}$ in patients with traumatic thoracic SCI. FAB117-HC is a putative therapeutic product whose active ingredient is expanded allogeneic AD-MSCs, and the current study design has partitioned participants into cohorts exploring FAB117-HC effectiveness in a randomized, controlled double-blind fashion. The estimated study completion date is in December of 2020 and, pending the publication of study results, could initiate broader clinical trials focusing on efficacy evaluation of AD-MSC-derived cell transplants in acute SCI.

\section{iPSCs}

Expanded understanding of biochemical modulators of stem cell maturation has allowed for the "un-differentiation" of terminally differentiated somatic cells, such as fibroblasts and peripheral blood cells, into pluripotent cells termed induced pluripotent stem cells. iPSCs were first generated by Drs. Takahashi and Yamanaka, who defined Oct3/4, Sox 2, c-Myc, and Klf4 as the 4 factors necessary to reverse differentiate adult fibroblasts into a stemlike cell. ${ }^{56,57}$ Concurrently, the authors identified Oct4, Sox2, NANOG, and LIN28 as being sufficient to reprogram fully differentiated somatic cells to express ESC-like qualities. ${ }^{69}$ As our understanding of differentiation and developmental biology has advanced, studies have increasingly turned to iPSCs as an ethical and readily obtainable alternative to ESCs. iPSC-derived neural progenitor cells (NPCs) have been shown to exhibit ESC-like neural differentiation potentials both in vitro and in vivo. ${ }^{61}$ In animal models of SCI, transplantation of these iPSC-derived NPCs has been associated with a reduced injury profile, tract regeneration, remyelination, and serotonergic reinnervation. ${ }^{34,39}$ In one study, prescreening of NPCs was required as a subset of transplanted NPC neurospheres resulted in formation of teratomas and subsequent functional deterioration. This increased tumorigenic potential has been associated with the viral mechanism used to generate iPSCs, as constitutional reactivation of the c-Myc transgene frequently occurs due to viral integration into the host cell genome. ${ }^{43}$ Recent solutions for overcoming this conundrum include the development of nonviral methods for creating iPSCs utilizing transposon-based reprogramming. ${ }^{67}$ Transplantation of transposon-induced, iPSC-derived NPCs has been shown to be safe while similarly promoting recovery of motor function in murine SCI models. ${ }^{49}$

Although human clinical trials studying the feasibility of iPSC-based cell therapy in SCI have yet to be finished, recent investigations have explored iPSC-derived NPC grafts in larger systems, including minipig SCI models. ${ }^{54}$ iPSC-derived NPCs were generated using a nonintegrating viral model and grafted into syngeneic recipients to investigate changes in functional recovery. Immunofluorescence staining for NeuN, synaptophysin, and GFAP, markers for identifying terminal neural cell subtypes, confirmed differentiated cell populations, while subsequent gene expression analysis revealed distinct neuronal and glial subtypes resembling the cellular organization of non-SCI mature pig CNS tissue. Further safety evaluation of iPSC-derived transplant therapies is required prior to administration in human acute SCI patients; however, positive results from diverse in vivo models hints to their therapeutic potential.

\section{The Future of Cell Therapy Strategies for Treating Acute SCl}

While scientific explorations into cell-based therapies for acute SCI has encouraged optimism for future therapeutic utility, clinical evaluation of stem cell transplants in traumatic SCI has moved slowly. Despite advances in the underlying biology of cell-based therapies in acute SCI, there has been a marked lack of large phase III trials exploring the therapeutic efficacy of stem cell transplantation. This paucity may exist for a number of reasons, including but not limited to the ethical challenges concerning the use of ESCs, the financial logistics associated with continued longitudinal functional and imaging analyses of patients receiving transplants, and patients' willingness to receive relatively novel therapies without extensive demonstration of safety.

Furthermore, advancement of cell transplant therapies into the clinical sphere has been hindered by modest efficacy or poor study design in a number of completed trials. A phase III study examining the effectiveness of cellbased therapy in patients with chronic SCI reported injection of BM-MSCs into the intramedullary and subdural spaces resulted in a weak therapeutic effect in only 2 of 16 patients. ${ }^{41}$ Despite the negative implication of this result, the limitations of this study encourage optimism for future clinical trials. The aforementioned study did not contain a control arm, preventing coordinators from identifying potential functional improvements in a controlled fashion. Additionally, it had been previously found that the application of multiple MSC injections was required to enhance neurological recovery. ${ }^{46}$ However, in the case of this study, only a single administration was given, due to government regulatory policy. Given these concerns, it stands to reason that additional clinical trials are required to validate the potential of stem cell-based therapy in treating acute SCI.

Currently, clinical efforts have focused on validating the safety and efficacy of somatic MSCs; a review of active and ongoing clinical trials in cell-based therapy in acute 


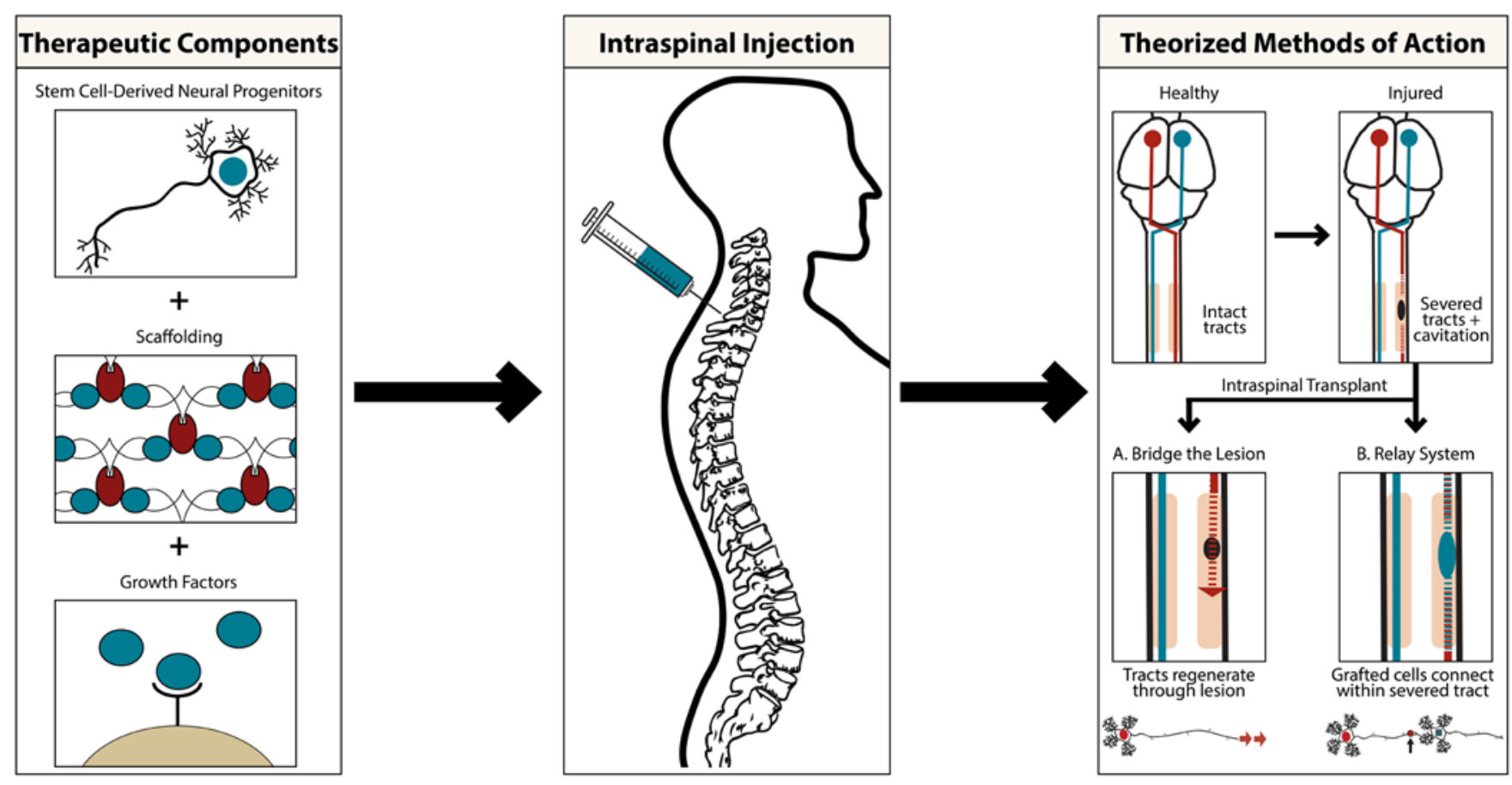

FIG. 1. A combinatorial strategy for cell-based therapies in SCl. Cellular transplantation may be augmented with a combination of growth factors, scaffolds, or other biomaterials that improve cell survival, engraftment, and differentiation. Intraspinal application of these therapies leads to engraftment of transplanted cells, which may promote neural regeneration through several proposed mechanisms. Engrafted cells may provide a conduit for host axonal outgrowth across the site of injury. Alternatively, engrafted cells may act as a relay system by synapsing with neurons located cranial and caudal to the injury site.

SCI revealed 8 of 9 studies (89\%) are focusing on MSC transplant as opposed to ESC-centric modalities (Table 2). Additionally, while most of these studies are administering stem cells intrathecally, exploration of other administration routes is also underway and would provide additional understanding on the optimal mode of treatment delivery. Finally, while the vast majority of completed and ongoing studies are phase I/II, preliminary evaluation of neuromuscular functionality using predefined scales of neurological impairment should prime the expansion of later-phase trials aimed at conclusively determining the effectiveness of current and future cell-based therapies for acute SCI.

\section{Therapeutic Adjuncts to Stem Cell Transplantation}

Therapeutic adjuncts including scaffolds, biomaterials, and immunotherapies could further promote spinal cord regeneration by augmenting stem cell survival, engraftment, and growth.

\section{Immunotherapy}

A major challenge following trauma to the spinal cord is the inhibitory nature of the posttrauma milieu, which is maintained by the presence of growth-suppressive molecules and signaling pathways. Despite the complexity of these inhibitory interactions, investigations have shown promise for immunotherapy in the treatment of acute SCI through both modulation of molecular signaling and regulation of the broader injury environment. ${ }^{5,29}$ When applied in rodent models of SCI, antibodies targeting a class of inhibitory molecules called myelin-associated inhibitors (MAIs) support increased locomotor function after injury. ${ }^{5}$ Other studies have explored controlling injury-associated inflammation through the administration of B-cell-depleting antibodies, demonstrating reduction of cell death, inflammatory signaling, and hindlimb dysfunction. ${ }^{8}$ However, before these therapies can be translated for use in patients, their safety must be clearly demonstrated by showing that these antibodies do not attack healthy myelin and do not elicit detrimental immunological responses.

\section{Biomaterial Scaffolds and Hydrogels}

Scaffolds and injectable hydrogels have been designed to augment stem cell engraftment, survival, and direct differentiation toward desired cell types after SCI (Fig. 1). Early work in synergistic treatment approaches involved implantation of extramedullary chitosan channels seeded with NPCs, theorizing that the channels would provide a supportive microenvironment for continued neural cell regrowth and axon extension. ${ }^{38}$ Since then, advances in biomaterials research, along with an improved understanding of stem cell biology, have allowed for diverse biomaterialcellular combinatorial approaches. A recent study examining methods to improve the survival of iPSC-derived OPCs posttransplantation demonstrated that simultaneous injection of a peptide-modified hyaluronan/methylcellulose-based hydrogel improved cell survival and proliferation in Sprague-Dawley rats subjected to compressive spinal injury. ${ }^{17}$ Additional assays demonstrated increased OPC migration and reduced teratoma formation in the rats 
receiving both OPCs and the injectable hydrogel. Another study demonstrated that co-introduction of a gelatin/methylacrylate hydrogel with NPCs decreased glial scar formation, reduced local inflammatory responses, and accelerated functional recovery after SCI. ${ }^{53}$

\section{Conclusions}

Cell-based therapies for acute SCI offer intriguing therapeutic solutions for a complex pathology. Recent advances in stem cell research have positioned cell-based approaches to SCI as potential therapeutic options for restoring sensorimotor function following acute SCI. Furthermore, combination approaches synergizing biomaterial constructs with stem cell transplants have proved promising. While more extensive validation is required before transitioning cell-based therapies into the clinic, current results and ongoing efforts suggest that stem cellbased approaches may play a major role in improving acute SCI therapy.

\section{References}

1. Abrams MB, Dominguez C, Pernold K, Reger R, WiesenfeldHallin Z, Olson L, et al: Multipotent mesenchymal stromal cells attenuate chronic inflammation and injury-induced sensitivity to mechanical stimuli in experimental spinal cord injury. Restor Neurol Neurosci 27:307-321, 2009

2. Adams BR, Golding SE, Rao RR, Valerie K: Dynamic dependence on ATR and ATM for double-strand break repair in human embryonic stem cells and neural descendants. PLoS One 5:e10001, 2010

3. Asterias Biotherapeutics. Asterias provides 24 month cohort 2 update for its OPC1 phase 1/2a clinical trial in severe spinal cord injury. Globe Newswire. July 31, 2018 (https:// globenewswire.com/news-release/2018/07/31/1544437/0/en/ Asterias-Provides-12-Month-Cohort-3-and-4-Update-for-itsAST-OPC1-Phase-1-2a-Clinical-Trial-in-Severe-Spinal-CordInjury.html) [Accessed January 10, 2019]

4. Blum B, Bar-Nur O, Golan-Lev T, Benvenisty N: The antiapoptotic gene survivin contributes to teratoma formation by human embryonic stem cells. Nat Biotechnol 27:281-287, 2009

5. Bregman BS, Kunkel-Bagden E, Schnell L, Dai HN, Gao D, Schwab ME: Recovery from spinal cord injury mediated by antibodies to neurite growth inhibitors. Nature 378:498-501, 1995

6. Cao Q, He Q, Wang Y, Cheng X, Howard RM, Zhang Y, et al: Transplantation of ciliary neurotrophic factor-expressing adult oligodendrocyte precursor cells promotes remyelination and functional recovery after spinal cord injury. J Neurosci 30:2989-3001, 2010

7. Cao Y, Sun Z, Liao L, Meng Y, Han Q, Zhao RC: Human adipose tissue-derived stem cells differentiate into endothelial cells in vitro and improve postnatal neovascularization in vivo. Biochem Biophys Res Commun 332:370-379, 2005

8. Casili G, Impellizzeri D, Cordaro M, Esposito E, Cuzzocrea S: B-cell depletion with CD20 antibodies as new approach in the treatment of inflammatory and immunological events associated with spinal cord injury. Neurotherapeutics 13:880-894, 2016

9. Charbord P: Bone marrow mesenchymal stem cells: historical overview and concepts. Hum Gene Ther 21:1045-1056, 2010

10. Charles ED, Fine PR, Stover SL, Wood T, Lott AF, Kronenfeld J: The costs of spinal cord injury. Paraplegia 15:302310,1978
11. Cheng H, Liu X, Hua R, Dai G, Wang X, Gao J, et al: Clinical observation of umbilical cord mesenchymal stem cell transplantation in treatment for sequelae of thoracolumbar spinal cord injury. J Transl Med 12:253, 2014

12. Cízková D, Rosocha J, Vanický I, Jergová S, Cízek M: Transplants of human mesenchymal stem cells improve functional recovery after spinal cord injury in the rat. Cell Mol Neurobiol 26:1167-1180, 2006

13. Darr H, Benvenisty N: Human embryonic stem cells: the battle between self-renewal and differentiation. Regen Med 1:317-325, 2006

14. De Ugarte DA, Morizono K, Elbarbary A, Alfonso Z, Zuk PA, Zhu M, et al: Comparison of multi-lineage cells from human adipose tissue and bone marrow. Cells Tissues Organs 174:101-109, 2003

15. Deshpande DM, Kim YS, Martinez T, Carmen J, Dike S, Shats I, et al: Recovery from paralysis in adult rats using embryonic stem cells. Ann Neurol 60:32-44, 2006

16. Frantz S: Embryonic stem cell pioneer Geron exits field, cuts losses. Nat Biotechnol 30:12-13, 2012

17. Führmann T, Tam RY, Ballarin B, Coles B, Elliott Donaghue I, van der Kooy D, et al: Injectable hydrogel promotes early survival of induced pluripotent stem cell-derived oligodendrocytes and attenuates longterm teratoma formation in a spinal cord injury model. Biomaterials 83:23-36, 2016

18. Gerrard L, Rodgers L, Cui W: Differentiation of human embryonic stem cells to neural lineages in adherent culture by blocking bone morphogenetic protein signaling. Stem Cells 23:1234-1241, 2005

19. Goodwin HS, Bicknese AR, Chien SN, Bogucki BD, Quinn CO, Wall DA: Multilineage differentiation activity by cells isolated from umbilical cord blood: expression of bone, fat, and neural markers. Biol Blood Marrow Transplant 7:581588,2001

20. Hoeben A, Landuyt B, Highley MS, Wildiers H, Van Oosterom AT, De Bruijn EA: Vascular endothelial growth factor and angiogenesis. Pharmacol Rev 56:549-580, 2004

21. Hofstetter CP, Schwarz EJ, Hess D, Widenfalk J, El Manira A, Prockop DJ, et al: Marrow stromal cells form guiding strands in the injured spinal cord and promote recovery. Proc Natl Acad Sci U S A 99:2199-2204, 2002

22. Hur JW, Cho TH, Park DH, Lee JB, Park JY, Chung YG: Intrathecal transplantation of autologous adipose-derived mesenchymal stem cells for treating spinal cord injury: a human trial. J Spinal Cord Med 39:655-664, 2016

23. Jeon SR, Park JH, Lee JH, Kim DY, Kim HS, Sung IY, et al: Treatment of spinal cord injury with bone marrow-derived, cultured autologous mesenchymal stem cells. Tissue Eng Regen Med 7:316-322, 2010

24. Kang KS, Kim SW, Oh YH, Yu JW, Kim KY, Park HK, et al: A 37-year-old spinal cord-injured female patient, transplanted of multipotent stem cells from human UC blood, with improved sensory perception and mobility, both functionally and morphologically: a case study. Cytotherapy 7:368-373, 2005

25. Keirstead HS, Nistor G, Bernal G, Totoiu M, Cloutier F, Sharp K, et al: Human embryonic stem cell-derived oligodendrocyte progenitor cell transplants remyelinate and restore locomotion after spinal cord injury. J Neurosci 25:4694-4705, 2005

26. Keller GM: In vitro differentiation of embryonic stem cells. Curr Opin Cell Biol 7:862-869, 1995

27. Kuh SU, Cho YE, Yoon DH, Kim KN, Ha Y: Functional recovery after human umbilical cord blood cells transplantation with brain-derived neutrophic factor into the spinal cord injured rat. Acta Neurochir (Wien) 147:985-992, 2005

28. Kumar R, Lim J, Mekary RA, Rattani A, Dewan MC, Sharif SY, et al: Traumatic spinal injury: global epidemiology and worldwide volume. World Neurosurg 113:e345-e363, 2018 
29. Lee JK, Zheng B: Role of myelin-associated inhibitors in axonal repair after spinal cord injury. Exp Neurol 235:3342, 2012

30. Lee KH, Yoon DH, Park YG, Lee BH: Effects of glial transplantation on functional recovery following acute spinal cord injury. J Neurotrauma 22:575-589, 2005

31. Liu F, Xuan A, Chen Y, Zhang J, Xu L, Yan Q, et al: Combined effect of nerve growth factor and brain-derived neurotrophic factor on neuronal differentiation of neural stem cells and the potential molecular mechanisms. Mol Med Rep 10:1739-1745, 2014

32. Lu LL, Liu YJ, Yang SG, Zhao QJ, Wang X, Gong W, et al: Isolation and characterization of human umbilical cord mesenchymal stem cells with hematopoiesis-supportive function and other potentials. Haematologica 91:1017-1026, 2006

33. Lu P, Wang Y, Graham L, McHale K, Gao M, Wu D, et al: Long-distance growth and connectivity of neural stem cells after severe spinal cord injury. Cell 150:1264-1273, 2012

34. Lu P, Woodruff G, Wang Y, Graham L, Hunt M, Wu D, et al: Long-distance axonal growth from human induced pluripotent stem cells after spinal cord injury. Neuron 83:789-796, 2014

35. McDonald JW, Liu XZ, Qu Y, Liu S, Mickey SK, Turetsky D, et al: Transplanted embryonic stem cells survive, differentiate and promote recovery in injured rat spinal cord. Nat Med 5:1410-1412, 1999

36. National Spinal Cord Injury Statistical Center: Spinal Cord Injury (SCI) Facts and Figures at a Glance. Birmingham, AL: University of Alabama at Birmingham, 2016 (https:// www.nscisc.uab.edu/Public/Facts\%202016.pdf) [Accessed January 10, 2019]

37. Ning G, Tang L, Wu Q, Li Y, Li Y, Zhang C, et al: Human umbilical cord blood stem cells for spinal cord injury: early transplantation results in better local angiogenesis. Regen Med 8:271-281, 2013

38. Nomura H, Zahir T, Kim H, Katayama Y, Kulbatski I, Morshead CM, et al: Extramedullary chitosan channels promote survival of transplanted neural stem and progenitor cells and create a tissue bridge after complete spinal cord transection. Tissue Eng Part A 14:649-665, 2008

39. Nori S, Okada Y, Yasuda A, Tsuji O, Takahashi Y, Kobayashi Y, et al: Grafted human-induced pluripotent stem-cellderived neurospheres promote motor functional recovery after spinal cord injury in mice. Proc Natl Acad Sci U S A 108:16825-16830, 2011

40. Nussbaum J, Minami E, Laflamme MA, Virag JA, Ware CB, Masino A, et al: Transplantation of undifferentiated murine embryonic stem cells in the heart: teratoma formation and immune response. FASEB J 21:1345-1357, 2007

41. Oh SK, Choi KH, Yoo JY, Kim DY, Kim SJ, Jeon SR: A phase III clinical trial showing limited efficacy of autologous mesenchymal stem cell therapy for spinal cord injury. Neurosurgery 78:436-447, 2016

42. Ohta Y, Hamaguchi A, Ootaki M, Watanabe M, Takeba Y, Iiri T, et al: Intravenous infusion of adipose-derived stem/ stromal cells improves functional recovery of rats with spinal cord injury. Cytotherapy 19:839-848, 2017

43. Okita K, Ichisaka T, Yamanaka S: Generation of germlinecompetent induced pluripotent stem cells. Nature 448:313317,2007

44. Osaka M, Honmou O, Murakami T, Nonaka T, Houkin K, Hamada $\mathrm{H}$, et al: Intravenous administration of mesenchymal stem cells derived from bone marrow after contusive spinal cord injury improves functional outcome. Brain Res 1343:226-235, 2010

45. Park HC, Shim YS, Ha Y, Yoon SH, Park SR, Choi BH, et al: Treatment of complete spinal cord injury patients by autologous bone marrow cell transplantation and administration of granulocyte-macrophage colony stimulating factor. Tissue Eng 11:913-922, 2005
46. Park JH, Kim DY, Sung IY, Choi GH, Jeon MH, Kim KK, et al: Long-term results of spinal cord injury therapy using mesenchymal stem cells derived from bone marrow in humans. Neurosurgery 70:1238-1247, 2012

47. Pera MF, Andrade J, Houssami S, Reubinoff B, Trounson A, Stanley EG, et al: Regulation of human embryonic stem cell differentiation by BMP-2 and its antagonist noggin. J Cell Sci 117:1269-1280, 2004

48. Ra JC, Shin IS, Kim SH, Kang SK, Kang BC, Lee HY, et al: Safety of intravenous infusion of human adipose tissue-derived mesenchymal stem cells in animals and humans. Stem Cells Dev 20:1297-1308, 2011

49. Salewski RP, Mitchell RA, Li L, Shen C, Milekovskaia M, Nagy A, et al: Transplantation of induced pluripotent stem cell-derived neural stem cells mediate functional recovery following thoracic spinal cord injury through remyelination of axons. Stem Cells Transl Med 4:743-754, 2015

50. Saporta S, Kim JJ, Willing AE, Fu ES, Davis CD, Sanberg PR: Human umbilical cord blood stem cells infusion in spinal cord injury: engraftment and beneficial influence on behavior. J Hematother Stem Cell Res 12:271-278, 2003

51. Satti HS, Waheed A, Ahmed P, Ahmed K, Akram Z, Aziz T, et al: Autologous mesenchymal stromal cell transplantation for spinal cord injury: A Phase I pilot study. Cytotherapy 18:518-522, 2016

52. Sekhon LH, Fehlings MG: Epidemiology, demographics, and pathophysiology of acute spinal cord injury. Spine (Phila Pa 1976) 26 (24 Suppl):S2-S12, 2001

53. Shin JE, Jung K, Kim M, Hwang K, Lee H, Kim IS, et al: Brain and spinal cord injury repair by implantation of human neural progenitor cells seeded onto polymer scaffolds. Exp Mol Med 50:39, 2018

54. Strnadel J, Carromeu C, Bardy C, Navarro M, Platoshyn O, Glud AN, et al: Survival of syngeneic and allogeneic iPSCderived neural precursors after spinal grafting in minipigs. Sci Transl Med 10:eaam6651, 2018

55. Syková E, Homola A, Mazanec R, Lachmann H, Konrádová SL, Kobylka P, et al: Autologous bone marrow transplantation in patients with subacute and chronic spinal cord injury. Cell Transplant 15:675-687, 2006

56. Takahashi K, Tanabe K, Ohnuki M, Narita M, Ichisaka T, Tomoda K, et al: Induction of pluripotent stem cells from adult human fibroblasts by defined factors. Cell 131:861-872, 2007

57. Takahashi K, Yamanaka S: Induction of pluripotent stem cells from mouse embryonic and adult fibroblast cultures by defined factors. Cell 126:663-676, 2006

58. Thinyane K, Baier PC, Schindehütte J, Mansouri A, Paulus W, Trenkwalder C, et al: Fate of pre-differentiated mouse embryonic stem cells transplanted in unilaterally 6-hydroxydopamine lesioned rats: histological characterization of the grafted cells. Brain Res 1045:80-87, 2005

59. Thomson JA, Itskovitz-Eldor J, Shapiro SS, Waknitz MA, Swiergiel JJ, Marshall VS, et al: Embryonic stem cell lines derived from human blastocysts. Science 282:1145-1147, 1998

60. Tropepe V, Hitoshi S, Sirard C, Mak TW, Rossant J, van der Kooy D: Direct neural fate specification from embryonic stem cells: a primitive mammalian neural stem cell stage acquired through a default mechanism. Neuron 30:65-78, 2001

61. Tsuji O, Miura K, Okada Y, Fujiyoshi K, Mukaino M, Nagoshi N, et al: Therapeutic potential of appropriately evaluated safe-induced pluripotent stem cells for spinal cord injury. Proc Natl Acad Sci U S A 107:12704-12709, 2010

62. Vazin T, Freed WJ: Human embryonic stem cells: derivation, culture, and differentiation: a review. Restor Neurol Neurosci 28:589-603, 2010

63. Veeravalli KK, Dasari VR, Tsung AJ, Dinh DH, Gujrati M, 
Fassett D, et al: Human umbilical cord blood stem cells upregulate matrix metalloproteinase-2 in rats after spinal cord injury. Neurobiol Dis 36:200-212, 2009

64. Via AG, Frizziero A, Oliva F: Biological properties of mesenchymal stem cells from different sources. Muscles Ligaments Tendons J 2:154-162, 2012

65. White SV, Czisch CE, Han MH, Plant CD, Harvey AR, Plant GW: Intravenous transplantation of mesenchymal progenitors distribute solely to the lungs and improve outcomes in cervical spinal cord injury. Stem Cells 34:1812-1825, 2016

66. Wislet-Gendebien S, Hans G, Leprince P, Rigo JM, Moonen G, Rogister B: Plasticity of cultured mesenchymal stem cells: switch from nestin-positive to excitable neuron-like phenotype. Stem Cells 23:392-402, 2005

67. Woltjen K, Michael IP, Mohseni P, Desai R, Mileikovsky M, Hämäläinen R, et al: piggyBac transposition reprograms fibroblasts to induced pluripotent stem cells. Nature 458:766770, 2009

68. Ying QL, Stavridis M, Griffiths D, Li M, Smith A: Conversion of embryonic stem cells into neuroectodermal precursors in adherent monoculture. Nat Biotechnol 21:183-186, 2003

69. Yu J, Vodyanik MA, Smuga-Otto K, Antosiewicz-Bourget J, Frane JL, Tian S, et al: Induced pluripotent stem cell lines derived from human somatic cells. Science 318:1917-1920, 2007
70. Zhang SC, Wernig M, Duncan ID, Brüstle O, Thomson JA: In vitro differentiation of transplantable neural precursors from human embryonic stem cells. Nat Biotechnol 19:11291133,2001

71. Zuk PA, Zhu M, Mizuno H, Huang J, Futrell JW, Katz AJ, et al: Multilineage cells from human adipose tissue: implications for cell-based therapies. Tissue Eng 7:211-228, 2001

\section{Disclosures}

Dr. Veeravagu reports being a consultant for NuVasive, Medtronic, and Johnson \& Johnson.

\section{Author Contributions}

Conception and design: Veeravagu, Jin, Medress. Acquisition of data: Jin, Medress. Analysis and interpretation of data: Jin, Medress, Azad, Doulames. Drafting the article: Jin, Medress. Critically revising the article: all authors. Reviewed submitted version of manuscript: all authors. Study supervision: Veeravagu.

\section{Correspondence}

Anand Veeravagu: Stanford University School of Medicine, Stanford,CA. anandv2@stanford.edu. 